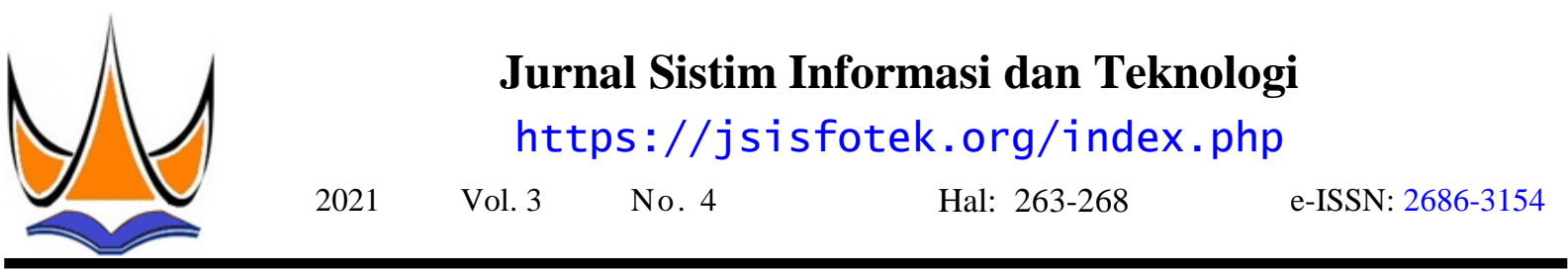

\title{
Tingkat Formulasi Model Soal dalam Permutasi Acak Menggunakan Algoritma Fisher Yates
}

\author{
Puji Chairu Sabila ${ }^{1 凶}$, Gunadi Widi Nur Cahyo ${ }^{2}$ \\ ${ }^{1,2}$ Universitas Putra Indonesia YPTK Padang \\ pujicha.sabila@gmai1.com
}

\begin{abstract}
The problem model in random permutations results in random randomization of the most commonly used questions in exam practice in education ranging from elementary school to college level and even some agencies that utilize exams to test one's abilities. This Problem Model can produce a high random percentage with more complex processes compared to analogues. Conduct Model Formulations on infinite questions so that they can be easily utilized without complicated calculations. The problems processed in this study are from 50 questions, and 12 students are sourced from the Information System Study Program of STMIK Logika, at Medan Indonesia state. Based on the collection of the question by the head of the study program in charge of the STMIK. Furthermore, the problem is saved into the database. The next stage is to randomize the question based on the number of students taking the exam. The problem has been randomized into a model formulation of the question in a random permutation of the question at the time of the Test practice. The result of the test on this question is a matter of courses. Randomized questions can form a problem model in random permutations based on many questions, the number of questions. All questions are made by lecturers who teach courses and help the study program in the teaching and learning process with the formulation of the problem model.
\end{abstract}

Keywords: Formulation Level, Problem Model, Random Permutations, Fisher Yates', Algorithm.

\begin{abstract}
Abstrak
Model soal dalam permutasi acak menghasilkan pengacakan soal - soal yang paling umum digunakan dalam praktik ujian pada pendidikan mulai dari tingkat Sekolah Dasar sampai Perguruan Tinggi bahkan beberapa instansi yang memanfaatkan ujian untuk pengujian kemampuan seseorang. Model Soal ini dapat menghasilkan persentase acak yang tinggi dengan proses yang lebih kompleks dibandingkan dengan analog. Mengadakan Formulasi Model pada soal-soal tak terhingga sehingga dapat dengan mudah dimanfaatkan tanpa perhitungan rumit. Soal yang diolah dalam penelitian ini dari 50 soal, dan 12 mahasiswa bersumber dari bagian Program Studi Sistem Informasi STMIK Logika Medan Indonesia. Berdasarkan pengumpulan terhadap soal tersebut oleh ketua program studi yang bertugas pada STMIK tersebut. Selanjutnya soal tersebut di disimpan ke dalam database. Tahapan selanjutnya melakukan pengacakan soal berdasarkan jumlah mahasiswa ikut ujian. Soal telah diacak menjadi formulasi model soal dalam permutasi acak soal pada saat praktik Ujian. Hasil dari pengujian terhadap soal ini adalah soal mata kuliah. Soal telah diacak dapat membentuk model soal dalam permutasi acak berdasarkan banyak soal, jumlah soal. Semua soal di buat oleh dosen yang mengajar mata kuliah dan membantu program studi dalam proses belajar mengajar dengan formulasi model soal.
\end{abstract}

Kata kunci: Tingkat Formulasi, Model Soal, Permutasi Acak, Algoritma, Fisher Yates.

(c) 2021 JSisfotek

\section{Pendahuluan}

Model soal merupakan penyajian soal kepada peserta didik yang sering dilakukan dengan frame work (kerangka kerja) sehingga lebih kompleks [1]. Model soal perlu dikembangkan agar meningkatkan efisiensi dalam pelaksanaan ujian, dengan perkembangan teknologi informasi pemanfaatan Model Soal semakin mudah dan berkembang seperti yang sering dikenal dengan Test From Home (TFH) pada beberapa instansi namun aplikasi yang tidak open acces atau tidak dapat dimanfaatkan oleh instansi lain. Model Soal sudah diterima di Masyarakat saat dilakukan pada tes Calon Pegawai Negeri Sipil (CPNS) akan tetapi belum dilakukan pada pendidikan untuk melaksanakan ujian [2]. Sehingga perlu membuat aplikasi Model Soal tersebut berbasis digital. Sesuai dengan tujuan pendidikan dalam Undang-Undang Republik Indonesia Nomor 20 Tahun 2003 Tentang Sistem Pendidikan Nasional. Pada dokumen tersebut disampaikan bahwa Pendidikan diselenggarakan secara demokratis dan berkeadilan serta tidak diskriminatif dengan tujuan hasil kemampuan peserta didik sesuai minat dan bakat dengan tanggung jawab [3].

Salah satu Model Soal yaitu ada pengacakan ini dapat menghasilkan persentase keacakan atau random yang tinggi dengan proses yang lebih kompleks dibandingkan dengan analog. Sehingga Model Soal yang muncul kepada peserta didik tidak dapat ditentukan. Meskipun secara komputasi tidak ada pengacakan yang sempurna karna di lakukan

Diterima: 31-08-2021 | Revisi: 01-10-2021 | Diterbitkan: 31-12-2021 | doi: 10.37034/jsisfotek.v3i4.76 
atau terjadi sekali. Hasil pengacakan secara komputasi disebut Acak Semu [4]. Model Soal dalam Permutasi Acak mengurangi masalah seperti pengadaan lembar soal ujian yang harus dicetak membuat pemborosan kertas dan tidak ramah lingkungan, perlunya pengadaan peralatan tulis peserta ujian, kecurangan peserta ujian, merepotkan panitia karena harus mengoreksi jawaban peserta ujian [5]. Permutasi Acak terjadi pada penelitian ini menggunakan algoritma Fisher Yate. Algoritma Fisher Yates ditemukan pada tahun 1938 oleh Ronald Fisher dan Frank Yates dalam buku mereka, Tabel Statistik untuk penelitian biologi, pertanian, dan medis [6]. Algoritma ini dapat menghasilkan permutasi acak dari suatu himpunan terhingga, dengan kata lain untuk mengacak suatu himpunan tersebut [7], [8], [9]. Algoritma ini menghasilkan bilangan acak semu yang sering digunakan untuk keamanan karna pembangkit secara aman [10].

\section{Metodologi Penelitian}

Penyelesaian Masalah Menggunakan Algoritma Fisher Yates. Penyelesaian masalah menggunakan algoritma Fisher Yates merupakan tahap yang dilakukan setelah tahap mengumpulkan data selesai. Dilakukan perancangan dan analisa pada permasalahan yang ada sesuai dengan data-data yang sudah terkumpul dengan langkah-langkah yang terdapat pada algoritma Fisher Yates, sehingga permasalahan-permasalahan tersebut dapat menemukan solusinya. Metode penelitian digambarka pada Gamabr 1.

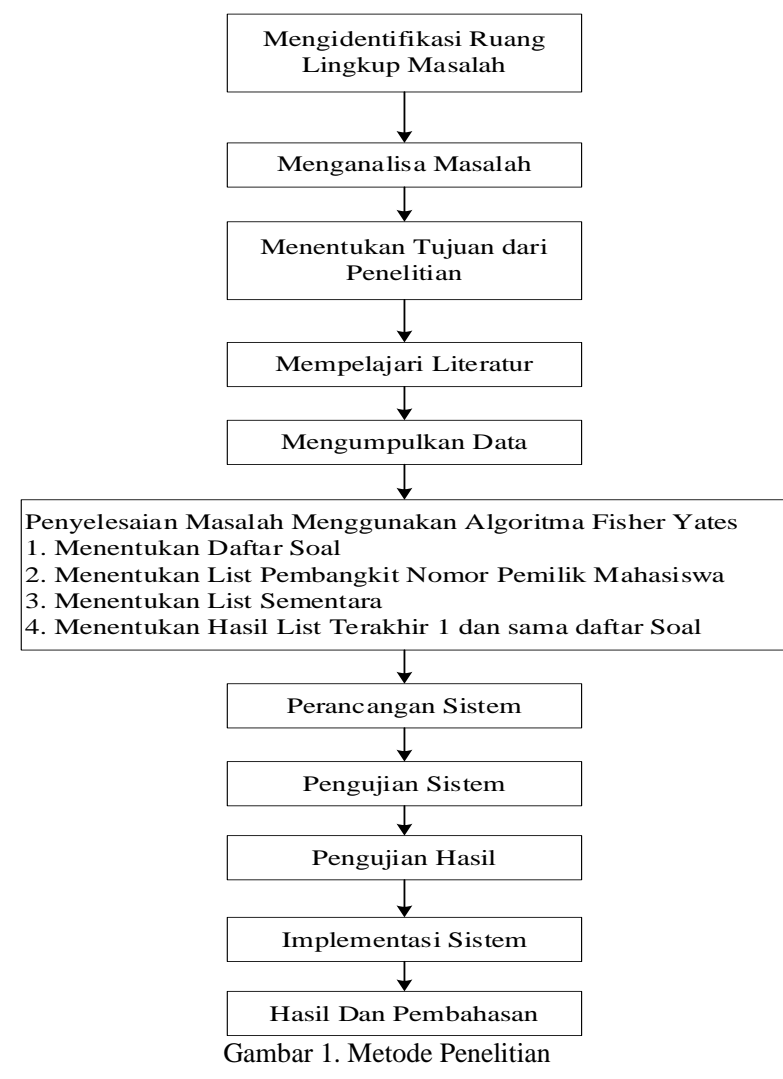

\subsection{Mengidentifikasi Ruang Lingkup Masalah}

Untuk memberikan penjelasan maupun menentukan ruang lingkup yang diteliti, tentukan dahulu ruang lingkup masalah yang akan diteliti. Menentukan ruang lingkup masalah merupakan langkah pertama yang dilakukan dalam penelitian.

\subsection{Menganalisa Masalah}

Menganalisa masalah ini merupakan suatu aktivitas yang dilakukan untuk alur selanjutnya dari penelitian, sehingga dalam melakukan penelitian dapat memahami permasalahan yang ada dengan batasan yang telah ditentukan. Berdasarkan masalah yang sudah ditentukan, diharapkan dapat melakukan analisa dengan baik.

\subsection{Menentukan Tujuan dari Penelitian}

Menentukan tujuan penelitian harus dilakukan pada tahap awal sebelum dilakukannya penelitian. Menentukan tujuan penelitian bertujuan untuk memberikan manfaat bagi penggunanya dalam melakukan penelitian. Tujuan penelitian dapat dikatakan suatu hasil yang diharapkan ketika penelitian telah selesai dilakukan, dan sesuatu yang akan dicapai dalam melakukan penelitian.

\subsection{Mempelajari Literatur}

Berdasarkan tujuan yang ingin dicapai, maka dibutuhkan kajian literatur sesuai dengan tujuan penelitian. Literatur yang sudah didapatkan akan dipilih dan dicocokkan dengan yang akan dipakai di dalam penelitian. Sumber dari literatur ini dapat berasal dari artikel, jurnal ilmiah mengenai algoritma Fisher Yates, serta referensi-referensi yang berhubungan dengan penelitian

\subsection{Mengumpulkan Data}

Tujuan dari pengumpulan data adalah untuk mendapatkan suatu informasi dari data-data yang dibutuhkan untuk penelitian agar mencapai tujuan yang diharapkan. Pada penelitian ini dalam melakukan pengumpulan data (Field Search) berupa pengetahuan-pengetahuan mengenai data soal atau model soal, peneliti melakukan wawancara langsung dengan pakar mengenai hal-hal yang berhubungan dengan objek penelitian.

\subsection{Penyelesaian dengan Algoritma Fisher Yates}

Penyelesaian masalah menggunakan algoritma Fisher Yates merupakan tahap yang dilakukan setelah tahap mengumpulkan data selesai. Dilakukan perancangan dan analisa pada permasalahan yang ada sesuai dengan data-data yang sudah terkumpul dengan langkah-langkah yang terdapat pada algoritma Fisher Yates, sehingga permasalahanpermasalahan tersebut dapat menemukan solusinya. 


\subsection{Perancangan Sistem}

Melakukan perancangan sistem merupakan langkah awal dalam membangun suatu sistem.

\subsection{Pengujian Sistem}

Tahap ini dilakukan untuk memberikan kepastian terhadap pemodelan soal yang sudah dibangun apakah sudah sampai pada tujuan yang diharapkan serta sudahkah bisa dilakukan implementasi terhadap pengguna.

\subsection{Pengujian Hasil}

Pada tahapan ini dijelaskan berupa hasil dari analisis pengolahan soal dan pengujian data yang telah dikerjakan dengan menggunakan algoritma Fisher Yates

\subsection{Implementasi Sistem}

Tujuan dari implementasi sistem ini dilakukan untuk melakukan perbandingan terhadap hasil yang diperoleh dengan analisa manual dengan sistem. Untuk membangun sebuah sistem, diperlukan komponen-komponen yang mendukung

\subsection{Hasil dan Pembahasan}

Pada tahap hasil, akan diperlihatkan suatu hal yang sukses dikerjakan oleh sistem yang dibangun. Sedangkan pada tahap pembahasan.

\subsection{Algoritma Fisher Yates}

Algoritma Fisher Yates adalah algoritma untuk permutasi acak dari sebuah himpunan yang tak terhingga sekalipun dalam pembentukan akhir sebuah nilai harus ditentukan. Logika pengolahan disajikan pada Algoritma 1.

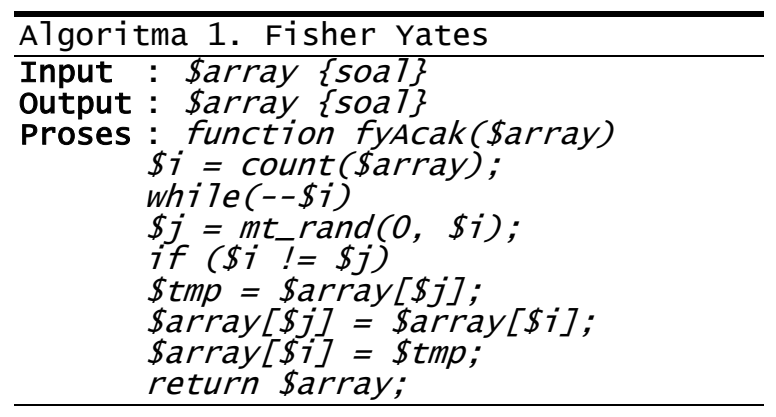

\section{Hasil dan Pembahasan}

Hasil dan pembahasan difokuskan pada proses pembuatan soal untuk pembentukan permutasi acak pada banyak soal yang akan dibentuk menjadi teracak hal inilah yang dimaksud dengan permutasi acak pada soal. Permutasi acak berdasarkan daftar soal yang berasal dari database. Kemudian masih ada proses lainnya yang harus dilakukan untuk keberhasilan proses permutasi acak yang akan diaplikasikan. Agar lebih jelas berikut alur proses permutasi acak soal yang disajikan pada Gamabr 2 .

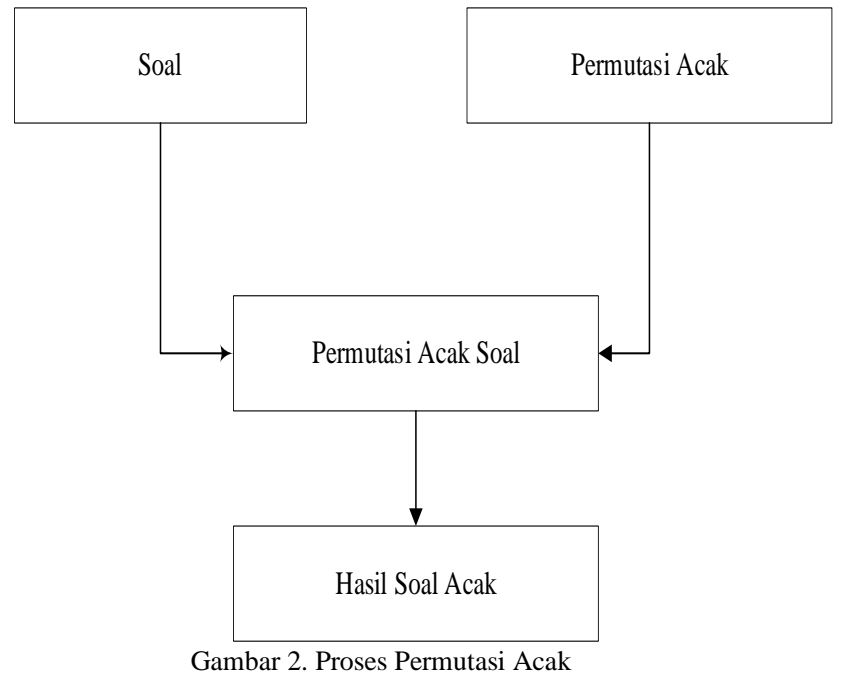

\subsection{Permutasi Acak Soal}

Pembentukan soal adalah bagaimana soal dibangun sehingga menjadi bahan untuk pengolahan permutasi acak. Pada dasarnya soal bersifat bebas pada saat di input sebagai kebutuhan peserta didik. Sehingga soal yang dipakai dalam pengujian adalah soal mata kuliah yang telah di rekam dan dikembangkan untuk permutasi acak soal. Teknis pembentukan soal disajikan pada Gambar 3.

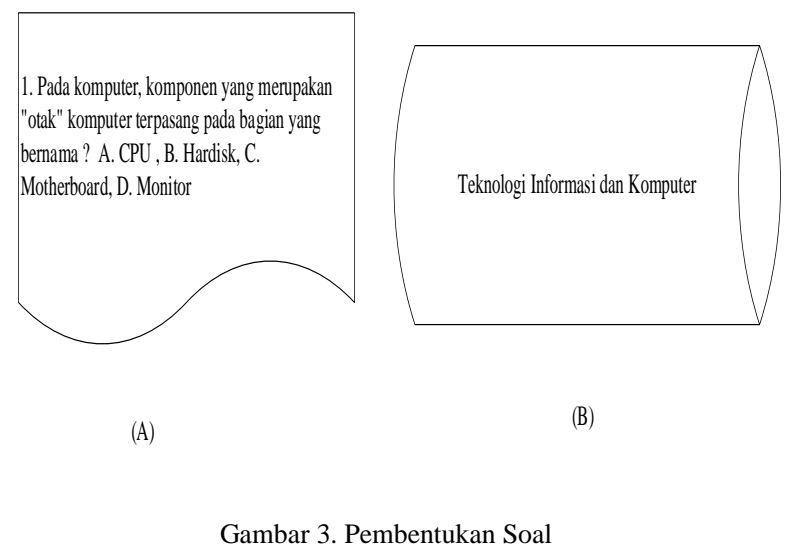

Pada Gambar 3 memberikan sebuah list soal setiap soal(A) terbentuk berdasarkan mata kuliah(B). Selanjutnya soal tersebut akan diaplikasikan atau diacak dengan permutasi acak menggunakan Algoritma Fisher Yates.

\subsection{Algoritma Fisher Yates untuk Permutasi Acak Soal}

Algoritma Fisher Yates adalah algoritma untuk permutasi acak dari sebuah himpunan yang tak terhingga sekalipun dalam pembentukan akhir sebuah nilai harus ditentukan. Hasil dari algoritma ini akan kembali ke himpunan tersebut dengan ilai telah teracak. Soal yang telah ditentukan seperti yang dijelaskan di atas akan membentuk sebuah himpunan yaitu satu baris dan lima puluh kolom, yakni dengan rumus 1 to $\mathrm{N}$. Logika pengolahan permutasi acak disajikan pada Algoritma 2. 


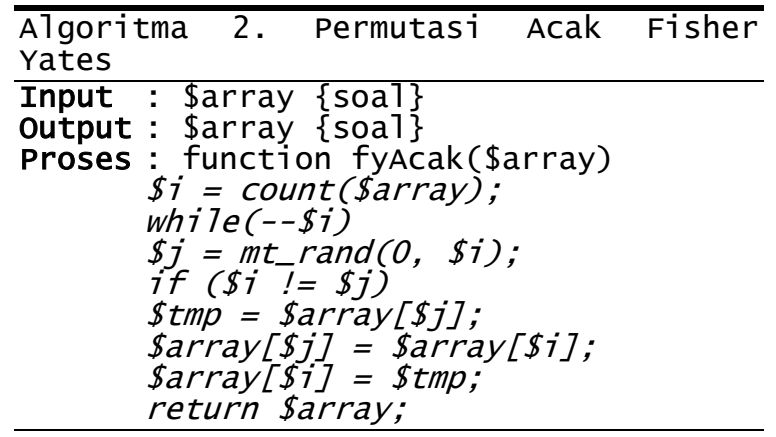

Memilih nomor acak adalah mengambil salah satu himpunan yang ada atau tersisa langkah ini bebas dilakukan oleh komputer secara otomatis, kemudian nilai yang terakhir dipindah ke nomor pilih acak yang baru. Berikut ini adalah algoritma memilih nomor acak dari sebuah himpunan. Buat himpunan baru berdasarkan nomor dipilih, sehingga nomor terpilih juga akan hilang dari himpunan lama. Proses ini terus berlanjut sampai himpunan data soal tinggal satu. Yaitu pemilihan nomor acak secara terakhir. Dan proses pengacakan berhenti. Berikut ini adalah algoritma himpunan baru berdasarkan nilai data terpilih. Dari hasil himpunan baru menghasilkan himpunan yang telah diacak dengan permutasi acak. Proses ini akan diakukan berulang kepada seluruh peserta yang ikut ujian.

\subsection{Hasil Perhitungan}

Perhitungan keseluruhan adalah perhitungan permutasi acak dengan algoritma Fisher Yates. Hal ini akan terus berlanjut sebanyak peserta yang mengambil ujian. Sehingga tidak akan pernah terjadi perulangan pada acak dan dipastikan setiap pengacakan akan menghasilkan nilai yang berbedabeda. Pada tabel berikut ini akan diberikan pemahaman proses dari algoritma ini. Sehingga hasil permutasi acak dengan algoritma Fisher Yates untuk pengacakan pertama dari himpunan "1 2345678 910111213141516171819202122232425 2627282930313233343536373839404142 4344454647484950 ” menjadi “"22 455042730 154319336481894684211292214752317 103744123312441164931832740382826 3425143920613 ".

\subsection{Pengolahan Terhadap Data Uji}

Pengolahan terhadap data uji adalah menentukan 50 soal pada mata kuliah. Soal dibuat oleh dosen pengampu mata kuliah. Setelah 50 soal terbentuk kemudian dilakukan pengacakan kepada masingmasing mahasiswa. Mahasiswa adalah peserta ujian. Pengacakan tersebut dilakukan dengan menerapkan algoritma Fisher Yates. Hal ini akan terus berlanjut sebanyak mahasiswa atau peserta yang mengambil ujian. Sehingga tidak akan pernah terjadi perulangan pada acak dan dipastikan setiap pengacakan akan menghasilkan nilai yang berbeda-beda. Berikut pengolahan terhadap data uji pada kasus sekali putaran dalam formulasi model soal. Setiap sekali pengacakan akan menyelesaikan seluruh himpunan, jika nomor atau soal telah di pilih maka akan di hapus dari himpunan. Hal ini akan terus berulang sampai himpunan selesai. Hal ini yang di lakukan oleh kita dalam mengambil keputusan dalam pengacakan dan seperti ini dapat di lakukan berbasi komputerisasi dengan algoritma Fisher Yates. 
Tabel 1. Pengolahan Data Uji

\begin{tabular}{|c|c|c|c|}
\hline Indek & Pilih & Himpunan Lama & Himpunan Baru \\
\hline 50 & 22 & $\begin{array}{l}1234567891011121314151617181920215023242526272829303132 \\
3334353637383940414243444546474849\end{array}$ & 22 \\
\hline 49 & 45 & $\begin{array}{l}1234567891011121314151617181920215023242526272829303132 \\
33343536373839404142434449464748\end{array}$ & 2245 \\
\hline 48 & 50 & $\begin{array}{l}1234567891011121314151617181920214823242526272829303132 \\
333435363738394041424344494647\end{array}$ & 224550 \\
\hline 47 & 4 & $\begin{array}{l}123475678910111213141516171819202148232425262728293031 \\
323334353637383940414243444946\end{array}$ & 2245504 \\
\hline 46 & 27 & $\begin{array}{l}123475678910111213141516171819202148232425264628293031 \\
3233343536373839404142434449\end{array}$ & 224550427 \\
\hline 45 & 30 & $\begin{array}{l}123475678910111213141516171819202148232425264628294931 \\
32333435363738394041424344\end{array}$ & 22455042730 \\
\hline 44 & 15 & $\begin{array}{l}123475678910111213144416171819202148232425264628294931 \\
323334353637383940414243\end{array}$ & 2245504273015 \\
\hline 43 & 43 & $\begin{array}{l}123475678910111213144416171819202148232425264628294931 \\
3233343536373839404142\end{array}$ & 224550427301543 \\
\hline 42 & 19 & $\begin{array}{l}123475678910111213144416171842202148232425264628294931 \\
32333435363738394041\end{array}$ & 22455042730154319 \\
\hline 41 & 3 & $\begin{array}{l}1241475678910111213144416171842202148232425264628294931 \\
323334353637383940\end{array}$ & 224550427301543193 \\
\hline 40 & 36 & $\begin{array}{l}1241475678910111213144416171842202148232425264628294931 \\
3233343540373839\end{array}$ & 22455042730154319336 \\
\hline 39 & 48 & $\begin{array}{l}1241475678910111213144416171842202139232425264628294931 \\
32333435403738\end{array}$ & 2245504273015431933648 \\
\hline 38 & 18 & $\begin{array}{l}1241475678910111213144416173842202139232425264628294931 \\
323334354037\end{array}$ & 224550427301543193364818 \\
\hline 37 & 9 & $\begin{array}{l}124147567837101112131444161738422021392324252646282949 \\
313233343540\end{array}$ & 2245504273015431933648189 \\
\hline 36 & 46 & $\begin{array}{l}124147567837101112131444161738422021392324252640282949 \\
3132333435\end{array}$ & 224550427301543193364818946 \\
\hline 35 & 8 & $\begin{array}{l}124147567837101112131444161738422021392324252640282949 \\
31323334\end{array}$ & 2245504273015431933648189468 \\
\hline 34 & 42 & $\begin{array}{l}124147567837101112131444161738342021392324252640282949 \\
313233\end{array}$ & 224550427301543193364818946842 \\
\hline 33 & 11 & $\begin{array}{l}124147567837103312131444161738342021392324252640282949 \\
3132\end{array}$ & 22455042730154319336481894684211 \\
\hline 32 & 29 & $\begin{array}{l}124147567837103312131444161738342021392324252640283249 \\
31\end{array}$ & 2245504273015431933648189468421129 \\
\hline 31 & 2 & 1314147567837103312131444161738342021392324252640283249 & 22455042730154319336481894684211292 \\
\hline 30 & 21 & 13141475678371033121314441617383420493923242526402832 & 2245504273015431933648189468421129221 \\
\hline 29 & 47 & 131413256783710331213144416173834204939232425264028 & 224550427301543193364818946842112922147 \\
\hline 28 & 5 & 13141322867837103312131444161738342049392324252640 & 2245504273015431933648189468421129221475 \\
\hline 27 & 23 & 131413228678371033121314441617383420493940242526 & 224550427301543193364818946842112922147523 \\
\hline 26 & 17 & 1314132286783710331213144416263834204939402425 & 22455042730154319336481894684211292214752317 \\
\hline 25 & 10 & 13141322867837253312131444162638342049394024 & 2245504273015431933648189468421129221475231710 \\
\hline 24 & 37 & 131413228678242533121314441626383420493940 & 224550427301543193364818946842112922147523171037 \\
\hline 23 & 44 & 1314132286782425331213144016263834204939 & 22455042730154319336481894684211292214752317103744 \\
\hline 22 & 12 & 13141322867824253339131440162638342049 & 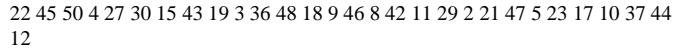 \\
\hline 21 & 33 & 131413228678242549391314401626383420 & $\begin{array}{l}22455042730154319336481894684211292214752317103744 \\
1233\end{array}$ \\
\hline 20 & 1 & 20314132286782425493913144016263834 & $\begin{array}{l}22455042730154319336481894684211292214752317103744 \\
12331\end{array}$ \\
\hline 19 & 24 & 203141322867834254939131440162638 & $\begin{array}{l}22455042730154319336481894684211292214752317103744 \\
1233124\end{array}$ \\
\hline 18 & 41 & 2031383228678342549391314401626 & $\begin{array}{l}22455042730154319336481894684211292214752317103744 \\
123312441\end{array}$ \\
\hline 17 & 16 & 20313832286783425493913144026 & $\begin{array}{l}22455042730154319336481894684211292214752317103744 \\
12331244116\end{array}$ \\
\hline 16 & 49 & 203138322867834252639131440 & $\begin{array}{l}22455042730154319336481894684211292214752317103744 \\
1233124411649\end{array}$ \\
\hline 15 & 31 & 2040383228678342526391314 & $\begin{array}{l}22455042730154319336481894684211292214752317103744 \\
123312441164931\end{array}$ \\
\hline 14 & 8 & 204038322867143425263913 & $\begin{array}{l}22455042730154319336481894684211292214752317103744 \\
1233124411649318\end{array}$ \\
\hline 13 & 32 & 2040381328671434252639 & $\begin{array}{l}22455042730154319336481894684211292214752317103744 \\
123312441164931832\end{array}$ \\
\hline 12 & 7 & 204038132863914342526 & $\begin{array}{l}22455042730154319336481894684211292214752317103744 \\
1233124411649318327\end{array}$ \\
\hline 11 & 40 & 2026381328639143425 & $\begin{array}{l}22455042730154319336481894684211292214752317103744 \\
123312441164931832740\end{array}$ \\
\hline 10 & 38 & 20262513286391434 & $\begin{array}{l}22455042730154319336481894684211292214752317103744 \\
12331244116493183274038\end{array}$ \\
\hline 9 & 28 & 202625133463914 & $\begin{array}{l}22455042730154319336481894684211292214752317103744 \\
1233124411649318327403828\end{array}$ \\
\hline 8 & 26 & 2014251334639 & $\begin{array}{l}22455042730154319336481894684211292214752317103744 \\
123312441164931832740382826\end{array}$ \\
\hline 7 & 34 & 20142513396 & $\begin{array}{l}22455042730154319336481894684211292214752317103744 \\
12331244116493183274038282634\end{array}$ \\
\hline 6 & 25 & 201461339 & $\begin{array}{l}22455042730154319336481894684211292214752317103744 \\
1233124411649318327403828263425\end{array}$ \\
\hline 5 & 14 & 2039613 & $\begin{array}{l}22455042730154319336481894684211292214752317103744 \\
123312441164931832740382826342514\end{array}$ \\
\hline 4 & 39 & 20136 & $\begin{array}{l}22455042730154319336481894684211292214752317103744 \\
12331244116493183274038282634251439\end{array}$ \\
\hline 3 & 20 & 613 & $\begin{array}{l}22455042730154319336481894684211292214752317103744 \\
1233124411649318327403828263425143920\end{array}$ \\
\hline 2 & 6 & 13 & $\begin{array}{l}22455042730154319336481894684211292214752317103744 \\
12331244116493183274038282634251439206\end{array}$ \\
\hline 1 & 13 & & $\begin{array}{l}22455042730154319336481894684211292214752317103744 \\
1233124411649318327403828263425143920613\end{array}$ \\
\hline
\end{tabular}

Jurnal Sistem Informasi dan Teknologi Vol . 3 No. 4 (2021) 263-268 


\subsection{Kesimpulan}

Algoritma Fisher Yates memiliki keunggulan dalam permutasi acak yang terlihat pada pelaksanaan ujian dimana ketika para peserta ujian mengerjakan ujian yang sama dengan soal dan pilihan jawaban yang berbeda. Berdasarkan dari data soal yang diberikan adalah hasil yang baik dalam mengacak soal sehingga kecurangan yang terindikasi akan dilakukan berhasil di hindarkan. Membangun sistem algoritma Fisher Yates untuk model soal yaitu menggunakan Visual Studio 2008 pada implementasi ujian.

\section{Daftar Rujukan}

[1] Xin, Y. P. (2012). Conceptual model-based problem solving: Teach students with learning difficulties to solve math problems. Brill Sense.

[2] Yendra, R., Marifni, L. \& Suryani, I. (20200 Klasifikasi Data Mining Untuk Seleksi Penerimaan Calon Pegawai Negeri Sipil Tahun 2017 Menggunakan Metode Naive Bayes. J. Sains Mat. dan Stat., 6(1). doi: http://dx.doi.org/10.24014/jsms.v6i1.9254.

[3] Indonesia, U. U. R. (2003). Sistem pendidikan nasional. Jakarta: Direktorat Pendidikan Menengah Umum. 2003.

[4] Susilo, J. \& Yenni, H. (2014). Perancangan Sistem Ujian Seleksi Penerimaan Mahasiswa Baru Dengan Menggunakan Algoritma Fisher-Yates Shuffle pada STMIK-AMIK RIAU. Sains dan Teknol. Inf., 3(2), 27-32.

[5] Hasan, M. A.m Supriadi, S. \& Zamzami, Z. (2017). Implementasi Algoritma Fisher-Yates Untuk Mengacak Soal
Ujian Online Penerimaan Mahasiswa Baru (Studi Kasus : Universitas Lancang Kuning Riau). J. Nas. Teknol. dan Sist. Inf., 3(2), 291-298, 2017 , https://doi.org/10.25077/teknosi.v3i2.2017.291-298.

[6] Fisher \& Yates, F. (1938). Statistical tables: For biological, agricultural and medical research. Oliver and Boyd.

[7] Hazra, T. K., Ghosh, R., Kumar, S., Dutta, S. \& Chakraborty, A. K. (2015). File encryption using fisher-yates shuffle. International Conference and Workshop on Computing and Communication (IEMCON), 1-7, doi: https://doi.org/10.1109/IEMCON.2015.7344521.

[8] Ade-Ibijola, A. O. (2012). A simulated enhancement of FisherYates algorithm for shuffling in virtual card games using domain-specific data structures. Int. J. Comput. Appl., 54(11). doi: https://doi.org/10.35335/mantik.Vol4.2020.

[9] Yusfrizal, D. Adhar, U. Indriani, E. Panggabean, A. Sabir, \& Kurniawan, H. (2020). Application of the Fisher-Yates Shuffle Algorithm in the Game Matching the World Monument Picture. International Conference on Cybernetics and Intelligent System (ICORIS), 1-6,

doi: https://doi.org/10.1109/ICORIS50180.2020.9320766.

[10] Musanna, F. \& Kumar, S. (2019). Novel fractional order chaosbased image encryption using Fisher Yates algorithm and 3-D cat map. Multimed. Tools Appl., 78(11). doi: https://doi.org/10.1007/s11042-018-6827-2.

[11]Dwita, M. R. (2020). Analysis of Acceptance And Use of Learning Management System Using The UTAUT Model (Case study: STMIK Logika): Analysis of Acceptance And Use of Learning Management System Using The UTAUT Model (Case study: STMIK Logika). J. Mantik, 4(1), 248-259. doi: https://doi.org/10.35335/mantik.Vol4.2020. 